The University of Akron

\title{
IdeaExchange@UAkron
}

Proceedings from the Document Academy

University of Akron Press Managed

December 2017

\section{Representativity and Complementarity in Tai Chi as Embodied Documentation}

Joacim Hansson

Linnaeus University, joacim.hansson@lnu.se

Please take a moment to share how this work helps you through this survey. Your feedback will be important as we plan further development of our repository.

Follow this and additional works at: https://ideaexchange.uakron.edu/docam

Part of the Library and Information Science Commons, and the Philosophy Commons

\section{Recommended Citation}

Hansson, Joacim (2017) "Representativity and Complementarity in Tai Chi as Embodied Documentation,"

Proceedings from the Document Academy: Vol. 4 : Iss. 2 , Article 11.

DOI: https://doi.org/10.35492/docam/4/2/11

Available at: https://ideaexchange.uakron.edu/docam/vol4/iss2/11

This Conference Proceeding is brought to you for free and open access by University of Akron Press Managed at IdeaExchange@UAkron, the institutional repository of The University of Akron in Akron, Ohio, USA. It has been accepted for inclusion in Proceedings from the Document Academy by an authorized administrator of

IdeaExchange@UAkron.For more information, please contact mjon@uakron.edu, uapress@uakron.edu. 


\section{Introduction}

How far is it possible to take the concepts "document" and "documentation" outside of the realm of our traditional understanding of them as highly dependent on materiality, representation, and function (Buckland, 1997; Francke, 2005)? The idea of a "document" has developed from traditional bibliography, beginning with Paul Otlet's three-dimensional documents and Suzanne Briet's theory of documents, as object representation in certain institutional contexts, such as libraries and museums. Recent research has brought an even wider understanding into play, including and defining oral documentation (Turner 2007, 2012a, 2012b), agency-oriented understanding of documents (Frohmann 2007, Irvine-Smith 2015) and functional definitions based on institutional belonging (Grenersen 2012, Latham 2012). Grenersen, Kemi and Nilsen have also suggested that natural landscapes can be read as documents (2016). All of these efforts are, with the notable exception of oral documentation, based on a general idea of materiality and permanence as a foundation for analysis even though that which is represented in a document does not necessarily have to be material - a novel can be treated as a document representing an idea or an ideal - the document as such is usually understood to have a material, structured dimension. For something to be considered a document or form the basis of a documentation process, there needs to be at least some kind of permanence, along with an active agent in the documentation process, a relation recently developed and discussed in Latham and Gorichanaz (2016).

The aim of this paper is to investigate what happens if we leave the criteria of materiality and permanence behind. How far can we stretch the definition of document or define a documentation process in a situation where neither the originary fact, or object, nor that by which this is represented is material or permanent?

Empirically, the paper is constructed as a case study where we focus on one specific example, the traditional Chinese practice of Tai Chi. The article is structured as follows: Firstly, Tai Chi is characterized as both philosophy and practice and, secondly, Tai Chi is discussed in relation to three theoretical ideas in documentation studies and Library and Information Science; (1) the theory of document representativity, as introduced by Suzanne Briet, (2) the theory of complementarity as introduced to document studies by Niels W. Lund, and (3) the theory of embodied information practice as proposed by Annemaree Lloyd and Michael Olsson. Finally conclusions are drawn suggesting an outlined discussion which may lead to a widened understanding of documents and documentation practices. 


\section{The basics of Tai Chi \\ Origins}

The meaning of Tai Chi is found within traditional Chinese Philosophy and can, in its modern form be said to combine principles from Daoism, Confusianism and Buddhism. Usually translated as "supreme ultimate," its conceptual roots stretch as far back as the enigmatic I Ching (1967). It was compiled as a book of oracles formulated approximately $3000 \mathrm{BCE}$, although written evidence of the existence of various elements of the current text do not appear until the 8th century BCE. I Ching consists of 64 hexagrams elaborated through elusive, poetic descriptions used as tools for divination. The possible combinations of the hexagrams is said to capture the whole of existence. The book has had an immense influence in Chinese history, not least through its profound significance for Confusius (551-479 BCE). I Ching is also the text which first introduces the components of Yin and Yang, the two complementary forces which, according to Daoist thought, build all of existence. Yin and Yang are also the first two hexagrams in I Ching, formulating the departure for all possible relations in the universe as described in the subsequent sixty two. Tai Chi as "supreme ultimate" is positioned outside of and, in linear thinking, before the appearance of Yin and Yang, thus manifesting the Daoist idea of no beginning or end. Tai Chi master Cheng Man Ching states that "[T]ai Chi is the mother of Yin and Yang. There is nothing it does not contain" (Man Ching 1985, 21). In his introduction to the I Ching, Richard Wilhelm writes that "[The] fundamental postulate is the 'great primal beginning' of that exists, t'ai chi - in its original meaning, the 'ridgepole'. Later Chinese Philosophers devoted much thought to this idea of primal beginning. A still earlier beginning, wu chi, was symbolised by the symbol of a circle. Under this conception, t'ai chi was represented by the circle divided into the light and the dark, yang and yin" (I Ching, $l v$ ). Tai Chi as such is symbolised by a combination of the Yin and Yang wave symbol circle, surrounded by the eight original hexagrams from the $I$ Ching, "conceived as images of all that happens in heaven and on earth" (I Ching, l) (see Figure 1).

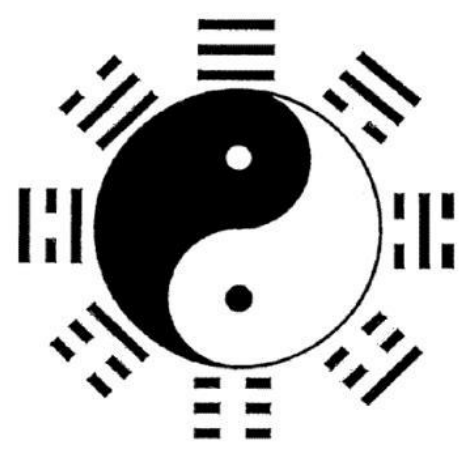

Figure 1: Tai Chi symbol with the eight original I Ching hexagrams. 
Tai Chi can be said to, on the one hand, represent the state of stillness which, in western scientific terms, would exist before the Big Bang, and on the other, the energy which is the heart of existence as a process, illustrated by the constant pendulum and between the creative Yang and the receptive Yin. This ultimate life energy is $C h{ }^{\prime} i$.

\section{Ch'i}

Ch'i is concurrently seen as the processual entity of life and internal energy in the body. Its place in Chinese philosophy is pivotal and it sits at the heart of the individual's connection between the inner self and the outer world. It is also seen as the very key to good health and longevity. Yang Jwing-Ming describes the content of the concept well:

Many Chinese believe that everything in the universe has its own energy field - every animal and plant, and even inanimate objects like rocks. Living things have a particularly strong energy field circulating through them. When this circulation is disturbed, illness results, and when it stops, there is death. Qi can be transferred from one object to another. In animals this Qi, which is often translated 'intrinsic energy' circulates throughout the body to keep every part vital and alive. Qi can be affected by the weather, the season, the food you eat, your mood and thoughts (Jwing-Ming 1996, 27).

Most aspects of traditional Chinese medicine aims at facilitating the flow of Ch'i. Some of the methods, such as acupuncture, have found their way also into western medical practice. Another method is to practice Tai Chi.

\section{Practice}

At the centre of Tai Chi, as a moving meditation practice, is the form, a defined sequence of postures combined through equally defined movements. As a corporeal practice, Tai Chi evolved during 13th century CE, when shaolin monk, Chang San-Feng formulated the balance between Yin and Yang through a distinct order of movements, creating the original form of Tai Chi (Olson, 2011). This original form is lost to us, but today, there is a romanticallycoloured movement within the Tai Chi community that strives for a re-creation of this ultimately authentic form. The system of movements and postures that Chang San-Feng developed is said to have come to him one day watching a fight between a crane and a snake. The movement of the animals struck him as physical manifestations of the Yin and Yang opposites, and he realised that bodily control, mental concentration, and the ability to change between soft movement and stillness was the key to human development. At the centre was softness, and in one of the so-called Tai Chi Classics (1990) attributed to him, it is written that: 
[o]nce you begin to move, the entire body must be light and limber. Each part of your body should be connected to every other part" (p. 87)

and

[i]n Long Forms your body should move like the rhythmic flow of water on a river or like the rolling waves of the ocean" (p. 94).

These two aphorisms capture the essence of the physical manifestation of Tai Chi, with its clear connection to Daoist origins, such as in Tao te Ching, chapter 78:

Nothing under heaven is softer or more yielding than water,

But when it attacks things hard and resistant, there is not one of them that can prevail. For they can find no way of altering it. That the yielding conquers the resistant and the soft conquers the hard is a fact known by all men, yet utilised by none.

(Lao Tzu, 1997, 82).

As the ultimate universal energy, Ch'i is that which connects everything in the universe into one, it is also present in everything, such as the physical and mental states of animals and humans. Chang San-Fengs revelatory observation of the crane and the snake is visible in all various Tai Chi forms existing today, with postures and movements imitating not only cranes and snakes, but horses, peacocks and tigers in a structured, flowing pattern of controlled opposites. These opposites are called the eight energies, all relating back to the original hexagrams of the I Ching; ward-off, roll-back, press, push, grab and pull, split elbow and body-strike (Zhenshan, 2013, 6). The moments of stillness which separate them from each other, creating a balance of movement in the form are symbolised by Lotus flowers, sunsets, mountains and lakes.

Today there are numerous schools of Tai Chi. They all build on the fundament laid out by Chang San-Feng, but originates in their current styles from the second half of the 19th century and are held together by a common core set of movements, connecting a number of postures which constitute the basis for all forms. Their emergence also coincides with popularisation of Tai Chi in China, before which the forms had been treated as arcane knowledge, tightly guarded by an initiated few. The combination of postures and the ways they are connected differ - the longest form consists of 108 postures and the shortest, 16. Different schools, or styles, are organised as family lineages, the most prominent being Chen and Yang. There are also some lineages that are less popular in the west, such as $\mathrm{Wu}, \mathrm{Wu}, \mathrm{Li}$, Sun and Xiong (DeMarco 2016, JwingMing 2001). The perhaps most notable difference between these is their relation 
to other forms of martial arts, something which, although interesting in itself, lies beyond the scope of this study.

Internationally, the most widespread style today is Yang Tai Chi, developed in the mid 19th century by Yang Luchan as a version of the somewhat older, Chen style. The most authoritative text on the Yang form, is Yang Chengfu's The essence and applications of Taijiquan from 1934 (Chengfu, 2005), one of the first books to have been written down about Tai Chi in any lineage. The Yang family lineage is upheld by fifth generation Grand Master Yang Jun (Ching \& Oh, 2015), and is being organised internationally by the International Yang Family Tai Chi Chuan Association (see Appendix).

Today, Tai Chi is increasingly popular all over the world with some estimated three millions practitioners outside of China. It is often compared to yoga, and its health benefits are well documented. Even so, Tai Chi's way to the west is disputed. Many consider Chen Man Ching (1902-1975), a student of Yang Chengfu, as the one who first taught Tai Chi in the USA as he established teaching in New York City in 1964. His influence is undisputed in terms of bringing common awareness of Tai Chi and also into popular culture through his prolific teaching, not only in person, but also through books and films, right up until his death. However, Tai Chi was in fact brought to the west several years earlier by two women who only recently have gained public recognition, Gerda Geddes in the UK, and Sophia Delza in the USA, who independently of each other, after years of study in China during the 1940s and 1950s, introduced their respective teachings to their students (Russo 2016). Both were professional dancers and dance teachers. Delza wrote and published what is arguably the first major book on Tai Chi in English (Delza 1961) introducing both basic Tai Chi philosophy, her perspective on Tai Chi as a dancer and a detailed description of the Wu style long form, which she taught in her studio in New York City until her death in 1996. Norwegian Gerda Geddes taught Tai Chi, Yang style, at the London School of Contemporary Dance from 1957 until her death in 2006. In 1991, she published a book on Tai Chi which not only contains fragments of a memoir, but also a thorough discussion of the symbolic aspect of various postures and movements within the form (Geddes 1991).

\section{Turning the form into documentation - a brief note on methodology}

When focusing Tai Chi from a document theory perspective, it is the form itself which is at the centre of interest. In the following, the term "the form" refers specifically to the long Yang style 103 form, consisting of 103 postures and movements. This limitation has some implications for the chosen material discussed in the analysis, and is one of convenience due to the limited character of this study.

In order to set some kind of relevant methodology, it is important to consider what is sought for. In the introduction I stated that the aim of this study is to see 
how far it is possible to take a discussion on documents and documentation in a case where some of the basic characteristics traditionally ascribed to a document is more or less absent - most notably materiality. To this we may now add another question which provide an alternative approach: is it possible to describe the relation between the form and the Ch'i, and more generally Yin and Yang, in terms of documentation? Does the Tai Chi form document the eternal power of everything through its illustration of the fundamental principles laid out in the I Ching?

In order to approach these three sides of the investigation, each chosen theoretical idea will be briefly characterised and discussed in relation to relevant aspects of Tai Chi philosophy and/or practice.

\section{Tai Chi and the representativity of document}

The idea of a document as an object of representation, as proposed by Suzanne Briet in 1951, has been dealt with in depth in contemporary studies (Buckland 1997, Day, 2006); her role in the French documentation movement has been chronicled by Maak (2004).

Briet (2006) provides two formal definitions of what a document is; (1) "a document is a proof in support of a fact" (p. 9), and (2) "any concrete or symbolic indexical sign (...), preserved or recorded toward the ends of representing, of reconstituting, or of proving a physical or intellectual phenomenon" (p.10). The notion of proof in relation to the definition of a document has been challenged by Frohmann $(2009,299)$. In this study, it is the second, definition which is of interest. Perhaps the most important part is that there is no immediate connection between the term "indexical sign" and materiality. If we allow ourselves to loosen the requirement of a material object used as a means for representation, it opens up a whole range of activities and phenomena that could be given a (potential) documentary status, such as dance performances or music. She goes on to describe "documentary fertility" of the indexical sign (document) by example an individual of a newly discovered antelope species who is caught and put in a representational position in a jardin des plantes, thus becoming a document, followed by a string of complementary documentation such as press releases announcing its arrival, cataloguing cards describing it as a whole object or in parts, photos taken of it, classification procedures, and ultimately theses and books written about it. She says, "The cataloged antelope is an initial document, and the other documents are secondary and derived" (Briet 2006, 11).

Let us consider this distinction between an initial document and the way in which it is supported by a secondary or derived level of documentation on the case of Tai Chi. If we accept the form as the initial document, representing the idea of a universal energy, Ch'i, as its "originary fact", this representation needs to be supplemented by derived documentation to define it as a document 
at all, given that Briet's definitions require an element of "proof". As there is no clear lineage between the form and the idea that it is representing - as between the newly discovered antelope and the individual antelope being cataloged - derived documentation becomes necessary to define. In Chinese philosophy, the idea of Ch'i and its relation to the complementary principle of Yin and Yang is of such stature that it may fill Briet's requirements for a symbolic "originary fact" of which the document, the form, provides a proof and a representation. If we accept this, we get the following basic relation for the subsequent analysis (Figure 2):

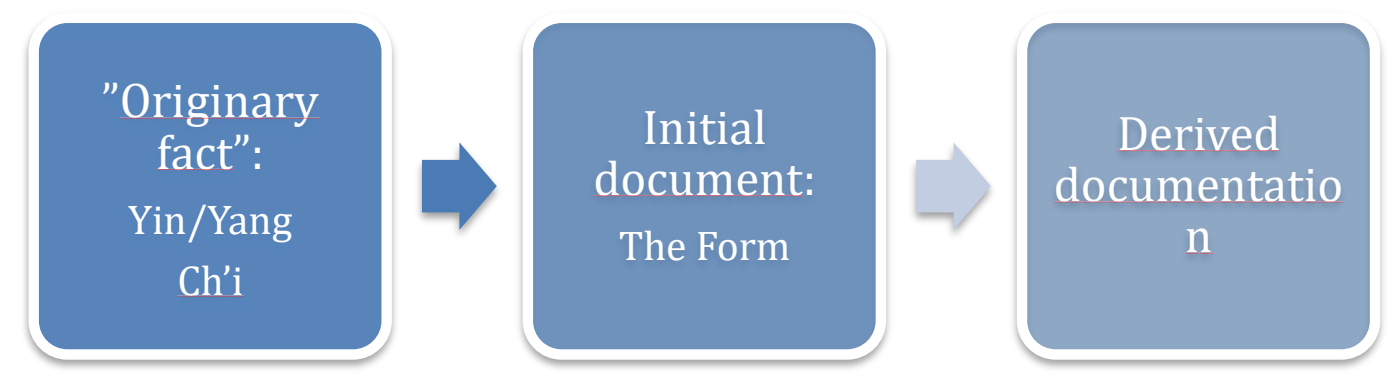

Figure 2: Documentary relations of Tai Chi form as initial document

Briet provides four levels of derived documentality ordered as 1st degree: "instruction", 2nd degree: "prospection", 3rd degree: "diffusion" and, 4th degree "organization". Being constructed for the institutional context of libraries and museums, each of these levels gradually move from the initial document towards explicit standards of bibliographical practice, or "documentography", as she suggests it to be termed. In order to ascribe meaning to the derived documentation of Tai Chi, we need to construct a structure for the vast literature on the subject which accompanies practitioners on all levels.

Derived documentation relating to the Tai Chi form can be broadly organised in four categories:

1. Philosophical documentation

2. Medical documentation

3. Instructive documentation and

4. Martial arts-related documentation

Based on their general content, we may further assign these categories three distinct functions; (a) ontological, (b) performative and (c) legitimising. Paraphrasing Briet's model on derived documentation (2006, 18-19), we may summarise the structure for Tai Chi documentation as seen in Table 1. 


\begin{tabular}{|l|l|l|l|}
\hline OBJECT & $\begin{array}{l}\text { ACTIVITIES } \\
\text { (connecting } \\
\text { to...) }\end{array}$ & FORM & FUNCTION \\
\hline Philosophical & $\begin{array}{l}\text { Meaning } \\
\text { Symbolism }\end{array}$ & $\begin{array}{l}\text { Books, } \\
\text { Treatises }\end{array}$ & Ontological \\
\hline Medical & $\begin{array}{l}\text { Health } \\
\text { Practice }\end{array}$ & $\begin{array}{l}\text { Peer Reviewed } \\
\text { Scientific Articles, } \\
\text { Integrative Medicine } \\
\text { Blogs, } \\
\text { 'New Age" Blogs. }\end{array}$ & Legitimising \\
\hline Instructive & $\begin{array}{l}\text { Practice } \\
\text { Tradition }\end{array}$ & $\begin{array}{l}\text { Lineage books } \\
\text { Association publ. } \\
\text { Video } \\
\text { (DVD/YouTube/Vimeo) }\end{array}$ & Performative \\
\hline $\begin{array}{l}\text { Martial Arts- } \\
\text { related }\end{array}$ & $\begin{array}{l}\text { Performance } \\
\text { Practice } \\
\text { Tradition }\end{array}$ & $\begin{array}{l}\text { Martial Arts Journals } \\
\text { Video } \\
\text { (DVD/YouTube/Vimeo) }\end{array}$ & $\begin{array}{l}\text { Ontological } \\
\text { Performative }\end{array}$ \\
\hline
\end{tabular}

Table 1: Derived documentation from the Tai Chi form as initial document

Philosophical documentation consists of a variety of documentation, ranging from the earliest findings of the I Ching on turtle shells, dating back to 8th century BCE, the original texts of Daoism, the so called Classics of Tai Chi, connecting Daoism to its manifestation in the form's movements and postures. The Classics of Tai Chi is not a uniform body of literature, but a diverse collection of highly influential texts preceding the now existing forms and family lineages, dating back to Chang San-Feng in the mid 13th century to texts up until the early 19 th century. Supplementing these are a vast commentary literature, drawing the line between meditative movement, internal energy flows and classical philosophy (Boedicker \& Boedicker 2009, Olson 2001).

Medical documentation connects Tai Chi to western scientific study of health benefits of regular Tai Chi practice. One example is the Harvard Medical School guide to Tai Chi (Wayne \& Fuerst 2013), combining research results from studies at the Harvard Medical School and its Osher Centre for Integrative Medicine with advice for time limited practice development. Empirical research is vast, most of which consists of tests of monitored Tai Chi practice in clinical settings as therapy for various diagnoses, both physical and mental. A good and representative example of this is Nery et al. (2015) testing Tai Chi intervention in treating myocardial infarction. In this category there is also plethora of books and New Age-oriented pamphlets and blogs on eastern practices relating to rapid health improvement, often combining elements from various cultural contexts, such as in Lee (2015), presenting Tai Chi as a moving meditation practice related to the Hindu concept of Chakra. 
Instructive documentation on Tai Chi consists primarily of books explaining the form, explaining it, posture by posture and movement by movement. Special emphasis are often put on traditional values and the importance of family lineages is demonstrated, such as in Muir (2008), de Graffenreid (2007) both describing Yang style forms and practices, Jwing-Ming (2001), analysing the origins of the $\mathrm{Wu}$ and $\mathrm{Li}$ styles or Delza (1961) going through the Wu form. Today there are also numerous instructional videos on platforms like YouTube and Vimeo, presenting the forms of various styles.

Martial arts-related documentation emphasises Tai Chi as a martial arts application, a tradition common in China, but less so today in western societies, treating it separately from the more overtly fight-related practices of Kung Fu. However, in the martial arts community, Tai Chi has its given place and role; the "supreme ultimate" is often seen as the very origin of martial arts through its manifestation of movement and stillness as a way of summoning Ch'i, the internal energy at the heart of all martial arts. The literature connecting Tai Chi practice to martial arts applications consists of a variety of forms such as martial arts journals, along with books well within the Tai Chi literature explaining the fight dimension of the slow and flowing forms (Jwing-Ming 1996).

Apart from these main categories there are also a vast number of electronic resources treating Tai Chi from different perspectives, mainly in the form of blogs or online journals of which the most renowned is Slanted Flying (for a brief list of online resources, see Appendix).

Unlike Briet's model there is no progression between the various categories here, as the relation between the initial document (the form) and its derivatives is somewhat different from that between, for example, a museum object and its various levels of description. Instead, the table should be read as a structured illustration of documentation deriving directly from the practice itself, the form. What binds the two models together is that the relation between the initial documents and their derivatives is one of mutual dependency in the documentation process. This dependency works both ways in that the initial document can exist without the derivate documentation, but our understanding of it and its ability to provide meaning is increased by comments and descriptions, and reversed the derivate documentation in its variety of forms is possible to read without immediate knowledge of the initial document, but dimensions of possible comprehension is lost without it.

Returning to the initial document, the form, and the possibility to apply the idea of representativity to it, we need to look at a few aspects of the definition given by Briet. It is clear that we have a connection between the form, the internal energy Ch'i and the concept of Yin and Yang, given their prominent placement as introductory hexagrams in the I Ching - Ch'ien/the creative and K'un/the receptive. The question that arises is how to formulate both the document and 
its representativity. Let us return to Briet's document definition and highlight some of what is written there. There are at least three elements in the definition worth commenting on:

A document is "any concrete or symbolic indexical sign (...), preserved or recorded toward the ends of representing, of reconstituting, or of proving a physical or intellectual phenomenon"

The form is possible to read as a symbolic indexical sign in the same way as a dance (Delza 1961, Geddes 1991). The formal structure developed from a limited number of animal-related postures and movements has clear connections to allegorical traditions in Chinese art and history. The legend of Chang San-Feng observing the crane and the snake is an example of such a connection as are postures and movements such as "snake spits out its tongue" and "carrying the tiger up the mountain" in the Yang form.

The form is being preserved through detailed instruction and the guarding of family lineages. This may today seem as mere tradition, but up until the popularisation of Tai Chi, which also in China emerged relatively late, during the late 19th and early 20th century, the lineages were preserving Tai Chi practice as esoteric teaching kept intact in monasteries and internal family practices. This is why books like Tai Chi secrets of the Wu and Li styles (JwingMing 2001) are devoted to unfolding the origins of different styles of the form in the long period prior to the opening up the practice to the public. It is also the reason for constant reference to the Tai Chi Classics, representing philosophical and instructive teachings on the form up until the early 19th century.

The aim of the form is to reconstitute ancient knowledge of the correspondence between the nature of the universe, through Yang and Yin, and the internal energy which is a sort of micro-manifestation of this, the Ch'i. The ability to show this reconstitution comes through the well-being-or lack thereof-of the practitioner.

Perhaps the most pivotal element of Briet's understanding is that of the proof. This is also the most problematic to define in relation to the form as a document representing universal laws of energy through internal corporeal energy. To call this symbolic, preserved reconstituting aim a proof would call for an expansion of the concept which is difficult to defend. Even so, defining the Tai Chi form as a document with some amount of representativity still seem possible. The connection between universal processes relating to the "supreme ultimate" and the Yang and Yin pendulum - being that which ultimately is represented by the form as a document - makes it reasonable to try specific tools for analysis. One such tool which has been suggested to document studies is the concept of complementarity. 


\section{Tai Chi and documentary complementarity}

The concept of complementarity in document studies was introduced by Lund (2004). There have been few major critiques and attempts to provide alternative analyses from it; most notably it has been further expanded upon by Skare (2009), Gorichanaz and Latham (2016) and Lund, Gorichanaz and Latham (2016). As will become apparent, the concept of complimentarity is relevant for the analysis of Tai Chi as a form of document. The representational problem that it presents us with very much comes down to the ability to provide an asynthesised analysis of the relation between the form as an initial document, its derived documentation and the problematic relation to that which in Briet's terminology is labelled the "originary fact" i.e. that which is being represented.

Complementarity as a concept has its roots in the theoretical construct made by Danish Nobel Laureate Niels Bohr (1885-1962) in quantum physics. His conclusion that, at a certain level, subatomic particles can be observed both as a wave and a particle, although never at the same time, gave rise to the idea of objects in general consisting of properties contradicting each other, necessarily co-existing to provide a whole. For Bohr, this was something purely related to quantum physics, but there has been an epistemological discussion ever since attempting to expand the idea of complementarity, and it is in this context we must see Lund's contribution.

Although spending years in developing an understanding of it, Bohr himself never defined complementarity an sich in a final way. Instead he gave several definitions, more or less formal, some of which are accounted for in Lund (2004) and Skare (2009). The most precise one, at least from a non-quantum physics point of view, is found in Plotinsky $(2013,5-6)$ as he provides the following definition of complementarity as:

(a) [a] mutual exclusivity of certain phenomena, entities, or conceptions; and yet

(b) the possibility of applying each one of the separately at any given point; and

(c) the necessity of using all of them, at different moments for a comprehensive account of the totality that we must consider.

Now, this is easy enough to see as we are dealing with a binary phenomenon (particle/wave), but more complicated as we take it into social science and humanities. In these areas description and analyses of phenomena has traditionally lent themselves to hermeneutical methodologies and phenomenological epistemology as discussed in Gorichanaz and Latham (2016), resulting in, to various degrees, subjective and holistic approaches. The advantage of this is, that a complex phenomenon is dealt with with respect to its complexity as dependent of certain factors, such as environmental, cultural, historical, political, economic or any other which may create a meaning- 
rendering context for the phenomenon in question, such as a document. The disadvantage is, as is emphasised by Lund (2004), a loss of detail and a difficulty in establishing analytically meaningful relations between parts of the phenomenon (document) both internally and externally.

There are, at least, two reasons to re-address Lund's attempt to bring Bohr's idea of complementarity into the realm of document studies. One has to do with Bohr himself. The very idea of quantum physics complementarity stems, at least in part, from his deep knowledge of Chinese philosophy and Daoism. Complementarity is the very manifestation of the Yin/Yang energy pendulum. This connection, although played down in his writing, came to show in various aspects of Bohr's life and legacy. One example, which in itself is interesting from a document point of view, is that when being admitted to the The Order of the Elephant, the highest royal recognition in Denmark in 1947, he created a Coat of Arms consisting of the Yin and Yang symbol, in red and black, crowned by the motto Contraria sunt complementum. Also, on Bohr's bust placed outside the main building of the University of Copenhagen, the influence of Daoist philosophy on his greatest achievement is recognised through the Yin and Yang circle are carved into the pedestal.

The second reason to re-address complementarity in the study of documents is a sense that Lund's argumentation has not yet been exhausted. When Skare (2009) questions Lund's argument, it is primarily the inclusion of the social element which is discussed. Lund argues that complementarity in document studies can be defined through three distinct elements, the material, the mental and the social. Just like Briet, he claims that the material must be in existence, although in a perhaps wider understanding than in the French treatise. Further, and perhaps more contentiously, he claims that a line can be drawn between the three fundamental properties on the one hand, and on the other, the concepts underlying almost all of Library, Information and Documentation studies; document, communication and information. The latter is claimed to carry a mainly mental dimension, a claim which perhaps can be made in the (deliberate?) absence of "knowledge" as a fourth fundamental concept. These in turn correspond to the a more narrow document analysis level as document, documentation and doceme, the latter signifying, in Lund's (2004) words "...a part of a document. A doceme can never be something in itself" (p. 100). Examples of a doceme are the chapters in a book or a photograph accompanying a newspaper article, completing the report of a specific event or phenomenon. Based on this model, it is possible to identify a dimensional, a process-oriented, and a document analytic grouping of the complementary elements pointed out by Lund (Table 2). 


$\begin{array}{lll}\text { Dimension } & \text { Process } & \text { Document Analysis } \\ \text { Material } & \text { Documentation } & \text { Document } \\ \text { Social } & \text { Communication } & \text { Documentation } \\ \text { Mental } & \text { Information } & \text { Doceme }\end{array}$

Table 2: Complementary elements suggested by Lund (2004)

Lund's argument, although elegant, points to the problem of taking a conceptual structure from one distinct area of inquiry, such as quantum physics, and applying it on another. Lund is of course aware of this and quotes Bohr in saying that the aim of research is not to grasp the phenomenon itself, but to find the best way of describing it (2004, 96). Still, Skare shows convincingly the difficulty of adding, specifically, a social dimension which according to the definition of complementarity should be possible to not only discover and analytically distinguish, but also would behave in a certain way against, and together with, the material and mental dimensions. Her argument is carried by the example of the covers of two editions of the same book, first and pocket, suggesting that both are steeped in social significance and symbolism in a way that is impossible to separate exclusively from the document itself. Her conclusion is that one needs to tone down the excluding character of complementarity, and instead treat it as a more inclusive concept. She summarises: " The word complementarity means both mutual exclusivity and completeness of description [...], for a scholarly analysis of a document, in my opinion, only the second sense is adequate" (Skare 2009, 840).

In an interesting discussion between Lund, Gorichanaz and Latham (2016) the two latter make somewhat similar claims, but from an explicitly phenomenological position stressing the necessity of an agency-based holistic analysis, a position more elaborately laid out in Gorichanaz \& Latham (2016). Lund, on the other hand, maintains the value of asynthesis, that is, the analytical distinction between different elements of the documents as a basis for understanding the complexity of the document in a non-hierarchical order. That is, neither social, nor mental or material dimensions can be said to be "above", or include the others, but possible to identify on equal terms as necessary for the completeness of the document.

While Skare connects her analysis to the example of a book, there is also another example pointed to by Lund $(2004,100)$. Here, he steps out of our traditional understanding of a document by addressing the event of a fashion show as a document. In Briet's terminology, fashion would be the originary fact, the catwalk as such would be the initial document, and the documentation following that event (reports, photographs, advertisements for clothes on display etc.) would be the derived documentation. Both the initial document and its derived documentation holds intrinsic elements which corresponds to the concept of doceme. This example is interesting in the analysis of the Tai Chi form in 
several ways. Firstly, its initial document is non-traditional most notably in its lack of immediate materiality in Briet's sense. Secondly, it is possible to define the derived documentation in terms of content as well as form, stemming fromand explaining-the significance of the initial document in relation to the originary fact, which in both fashion and Tai Chi is, arguably, difficult to define. Again, it is the social dimension which causes problems. In order to solve this, we can distinguish between two types of complementarity, one intrinsic, defined by elements within the initial document itself, and one extrinsic, defined by, and depending on, elements from outside of the initial document.

Given the argumentation concerning the Tai Chi form as a document representing the complementarity universal energy of Ch'i, it is possible to illustrate the intrinsic complementarity of the form itself, that is, the initial document, as seen in Figure 4:

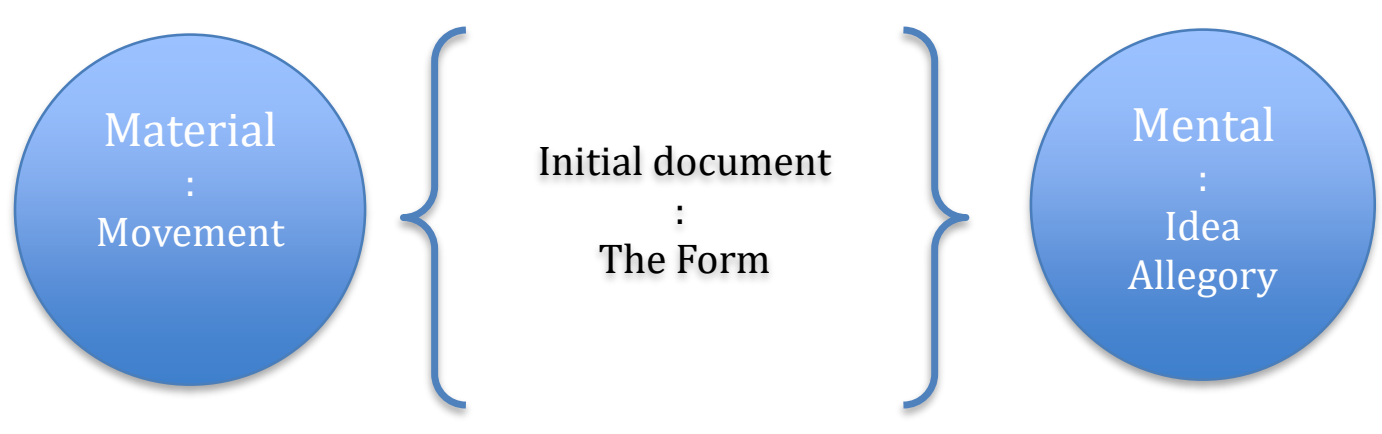

Figure 4: Intrinsic document complementarity.

In this, the social dimension is kept out of the equation. Included is only that which can be defined from within the form itself. The material element is represented by the bodily movement as such, necessary for the very existence of the document. If the practitioner stops and walks away, the document simply ceases to exist. The mental element is represented by the allegorical dimension of the form which is necessary to provide its meaning. Without the allegorical element referring nature and animal postures, the form would just be a random sequence of weird standing positions and the basis for defining it as a document would be lost. However, it is possible to claim this intrinsic complementarity sufficient for understanding the various document properties in an analysis based on a-synthesis in order to provide the complete document.

One interesting problem occurs, however, regarding the intrinsic complementarity, namely its contingency, or lack of permanence. If the form, the initial document, ceases to exist when the practitioner has completed it and walks away, how is it possible to return to it and claim that it still exists? Every 
time a form is completed, it ceases to exist and every time a new form is commenced, it "reappears" in a different version, both through the same individual doing the form a second time, or through different individuals doing it at a different time or location. Although the movement is the only thing that holds the document together, it is also the one thing which is impermanent this is instead kept through the mental element, supplemented by the derived documentation which in this regard might be said to acquire an ontological function.

In this analysis, the social element is not per se necessary. However, if we include it as a determinant of meaning, formulated outside the form for instance through derived documentation such as the Tai Chi Classics or through experienced heath benefits of the individual as result of persistent practice, it becomes an extrinsic complementary element in an analysis based on asynthesis. What this element does in a complementary setting can, which both Skare and Gorichanaz \& Latham point out, be disputed. The most common way of addressing social influence on a document is to create a holistic model as is seen in Gorichanaz \& Latham (2016), where the material document is connected to individual agency in what is called "documental becoming" (p. 1118), creating the prerequisite for a document to achieve meaning. Without the connection between the document as a physical object and the individual's recognition of it, the document becomes a "dormant" information object. Striving to attain the exact opposite of Lund, a holistic analysis blending all (intrinsic, extrinsic, abtrinsic, and adtrinsic) parts of a document within a system setting, the social becomes not only the context of a document, but it acquires a determinant position. An analysis using a-synthesis does not necessarily contradict this, but rather tries to avoid the risk of falling into a general blur which may occur in letting all aspects blend together, determining each other in all directions. Instead, it emphasises the social element of a document as something important, possible to isolate for analytical purposes. The question is, how? Tai Chi provides us with an interesting example. If speaking in social terms of Tai Chi there are two aspects to take into special consideration; (a) the cultural dimension where Tai Chi as applied in the west compares to that in China and (b) Tai Chi as a social practice.

The cultural dimension as basis for a social complementary element is interesting through the transformation of meaning which takes place in its moving out of the original Chinese cultural sphere, where its allegorical and ontological references are given in the intellectual tradition as part of that which constitutes Chinese society. During the introduction of Tai Chi in the west during the late 1950s and early 1960s, these cultural markers had to be learned intellectually by most practitioners and incorporated into a cultural understanding which is accessible and, in a sense restricted to the practice itself, meaningful. This restricted sense takes its expression in the fact that most Tai Chi practitioners in, for instance, Sweden or the USA do not immediately turn 
into full scale Daoists, but learn of Daoist principles as part of the practice, immediately meaningful as a complement to the health motivation which perhaps was the practitioner's reason to seek out Tai Chi classes in the first place. In these two situations, cultural inclusion into the practice looks very different. They are necessary and important, but of such distinct character that it becomes meaningful to treat them separately in the study of the Tai Chi form as a document.

The second aspect which must be taken into consideration is the practice itself as a social undertaking. Although the form as such is performed individually, the social aspect of Tai Chi is important and one in which the social differences are most clearly visualised between western and Chinese practice. Few start doing Tai Chi on their own, despite the numerous instruction films occurring on platforms such as YouTube and Vimeo. Instead Tai Chi is essentially a group activity. Group practice functions both as a help for individual improvement and as a way of gaining increased meditative focus. In western settings, the Tai Chi class is the most common social form, while in China, tradition is that Tai Chi is preferably executed outdoors, together with others, not just in organised "class" settings, but spontaneously in open spaces such as parks. Doing Tai Chi outdoors is part of the Daoist connection, where oneness with nature, air, heaven, wind and weather plays an important role. Doing Tai Chi outdoors, in togetherness with others, creates a connection between people which places them in the common flow of energy, creating a collective sense of Ch'i.

The social element of the form as a document can therefore be seen as functioning together with the mental (allegorical) and the physical (the movement) elements to form a whole. It can look different in different social and cultural settings and this to the extent that it is possible, and perhaps necessary, to identify the social as distinct from the other elements, as its ways of creating meaning varies depending on whether you find yourself in a small town Tai Chi class in southeast Sweden or in a park in Kunming. Identified as extrinsic to the form, its function thus becomes such that it may be described as a background or a platform for the form, putting it in relation to the intrinsic elements of the document as is seen in Figure 5: 

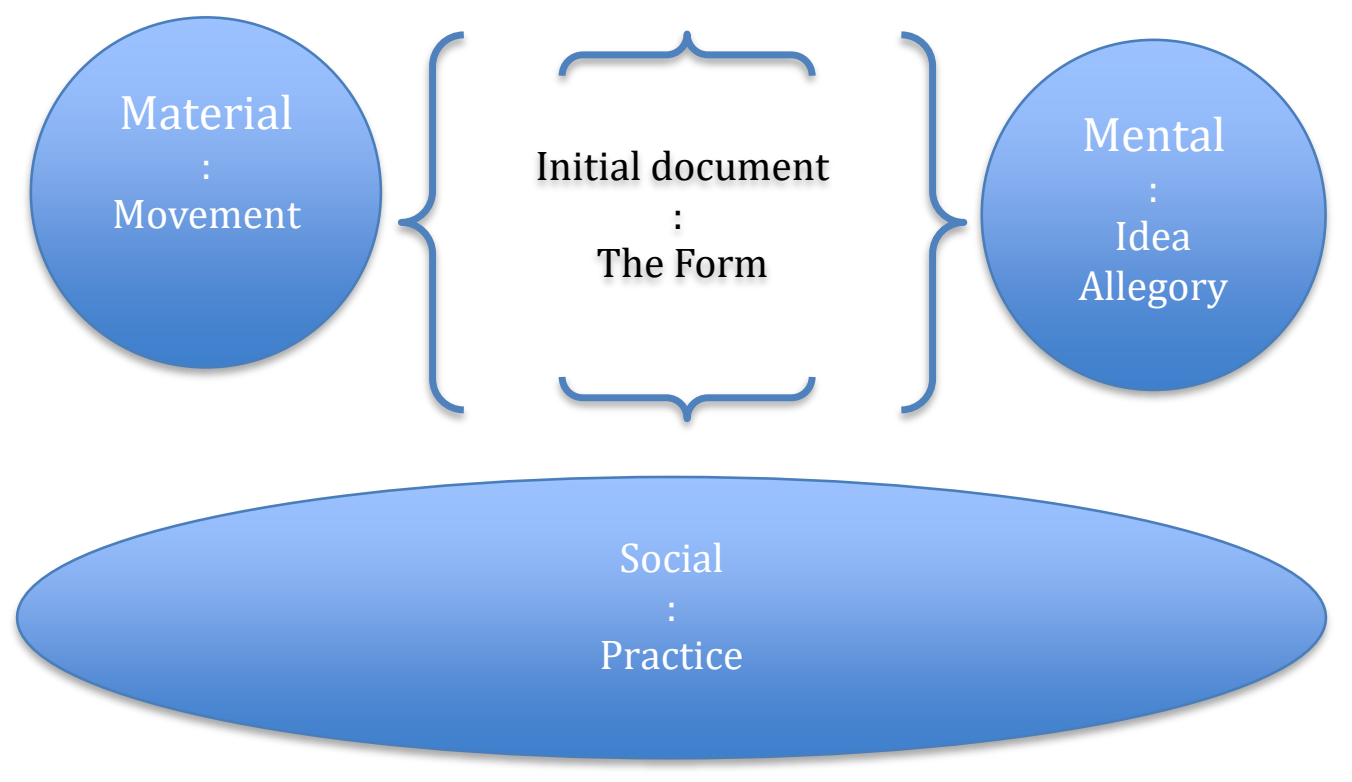

Figure 5: Extrinsic document complementarity.

\section{Conclusion - towards Embodied Documentation}

As we have now established the Tai Chi form as a kind of document through its representativity and discussed complementarity as a conceptual tool, thus concluding that it is possible to discuss also "originary facts" which are material neither in themselves nor in that which they represent, it is now possible to go one step further and consider a way of talking about immaterial documents and documentation in a somewhat broader sense. In doing so, the argumentation made in this paper can be extended to comprise also other forms of symbolic corporeal action, such as dance or pantomime as perhaps the most immediate examples. How then are we to understand phenomena like these in a documentary way? One suggestion is to talk about them as embodied documentation.

In Library and Information Science, corporeal aspects and practices have only rarely been addressed. When they have, it has almost exclusively been in the context of learning processes or information literacy practices, leading to the concept of "embodied information practice". Annemaree Lloyd and Michael Olsson presented their take on this particular field of inquiry at the 2016 CoLIS conference by drawing on their own extensive research on such diverse groups as nurses, firemen, refugees, archaeologists and actors, all professions and lifesituations in which sensual and bodily experiences play an important part in learning as well as in gathering and evaluating information in order solve a problem, perform a task or simply to move forward in life (Olsson \& Lloyd, 2016). They define embodied information practice in terms of sites of knowledge which: 
- " "are always situated (in situ);

- $\quad$ are expressed corporeally, and central to actors understanding the social and epistemic modalities of the landscape;

- act as a site for know-how knowledge, which cannot be expressed in written form (e.g. learning how to recognise an artefact; learning how to write, learning how to read a fire)

- are local/nuanced, drawing from expertise in situ and may be contingent and only at 'the moment of practice'." (Olsson \& Lloyd 2016, no page)

This summary of the essence of embodied information practice is both interesting in itself and relevant to discuss in relation to the analysis of Tai Chi as embodied documentation. So, let us see how it fits. As described in the argumentation of this paper, Tai Chi can well be seen as site of knowledge which

- is always situated, in situ. The initial document, the form, is performed consciously in specific settings and only there - be it evening classes or morning exercises in a park.

- is expressed corporeally and, possibly, act as a site for know-how knowledge.

The idea of know-how knowledge is interesting as it is central to the learning aspect of information practice. It relates primarily to learning as goal oriented. To learn and internalise corporeal know-how means that the practitioner increases his or her ability to solve tasks and problems relevant for the specific profession or situation, i.e. how to put out a fire or internalise a part in a Shakespeare play. Also in Tai Chi, there is a clear element of know-how and a strong learning component. This comes through in the master/student relation which can be seen on many levels, but also in the part of the derived documentation which explicitly focus instruction and which often takes the character of "carrying a lineage" from one generation to another from one experienced teacher to less experienced teachers and from these down to the inexperienced beginner. The aim of these learning experiences is, however, somewhat different from the solving of tasks and problems in the sense of information practices as it rather see the forgetting of learning as a goal. The forgetting of learning has to do with reaching a meditative stage while going through the form where the body and mind is so open that the Ch'i can flow uninterrupted by thought and intellect. In achieving this, Tai Chi holds a strong element of unlearning, taking place as the opposite movement from learning, in itself manifesting the universal relation between the receptive (learning) and creative (un-learning). To reach the stage of un-learning in Tai Chi takes many years and significant dedication on behalf of the practitioner. As the ultimate goal of Tai Chi instruction is a process of un-learning, it does not come as a 
natural consequence that the truly advanced Tai Chi practitioner is a good teacher - it simply means that he or she is able to achieve a free flowing Ch'i.

The last point by Olsson \& Lloyd is also relevant to Tai Chi practice, being

- local/nuanced, drawing from expertise in situ and is contingent, existing only in the "moment of practice".

This takes us back to the core of the research question for this study; the immateriality and impermanence of the form as a document and how to treat that. In order to define the Tai Chi form as a document and addressing a model to analyse it, it has been necessary to include the derived documentation as a basis for the stability and regulation of the practice as it has gone down through time. Would it therefore be reasonable to talk of Tai Chi as an embodied documentation practice? In some sense, yes, it probably would. Here, however, where the aim has been to discuss Tai Chi as a document, the practice element needs to be played down. That the criteria concerning the embodiment part of embodied information practice corresponds well to that which has been identified here is beyond doubt. However, there is reason to hesitate, as information practice contains two concepts which are difficult to include in the analysis of Tai Chi as document; "information" and "practice". Information as a tool for reading a situation or solving a problem is crucial for the understanding of the role of embodiment - Olsson \& Lloyd formulate it like this:

"[i]n the practice field, embodiment and corporeal information are central to understanding practice as a social site, where bodies are viewed as referencing the nature of practice (social site), the performance of work and the demonstration of practical- reasoning and know-how" (2016, no page).

The representativity of the Tai Chi form should not be confused with an ability, or aim, to "inform" of that which is represented. If anything, it should, as suggested by Olson (2001), be read as a representational extension of the principles and energies defined in the I Ching, manifested in the bodily energy of Ch'i, in the same sense that the choreography of a ballet should not necessarily be read as informing a scripted content, but instead formulating a documentary representation of an idea. This also puts a question mark for the use of the concept of "practice" which in information practice research, is largely based on broad strokes of general practice theory (Nicolini 2012) relating to productive learning experiences aimed at solving tasks or reading complex situations. This understanding of practice does not apply to what the Tai Chi practitioner submits to, although further studies of this, based on the approaches taken by Olsson and Lloyd would be much welcomed. In the same way, it does not apply to other activities that the study of Tai Chi may be applicable to, such as dance performances, pantomime or, indeed, as Lund 
points out, fashion shows. Therefore I suggest embodied documentation as a concept which may instruct us in the reading of Tai Chi. If this suggestion is found adequate, it will be possible to use in an extended analysis of other symbolic corporeal expressions as well and from that, both our understanding of documents and documentation would benefit greatly.

\section{References}

Boedicker, F. \& Boedicker, M (2009) The philosophy of Tai Chi Chuan: wisdom from Confusius, Lao Tzu and other great thinkers. Berkeley, CA: Blue Snake Books.

Briet, S. (2006) What is documentation? English translation of the classic French text. Langham, ML: Scarecrow Press.

Buckland, M. (1997) "What is a 'document'?". Journal of the American Society for Information Science, Vol. 48 (9), 804-809.

Chengfu, Yang (2005) The essence and applications of taijiquan: translated by Louis Swaim. Berkeley, CA: Blue Snake Books.

Ching, G. \& Oh, G. (2015) "The most popular martial art in the world". Kung Fu/Tai Chi, May/june 2015, 18-27.

Day, R. (2006) "'A necessity of our time': documentation as 'cultural technique' in What is Documentation?". What is documentation? English translation of the classic French text. Langham, ML: Scarecrow Press, 47-69.

Delza, S. (1961) T'ai Chi Ch'uan: body and mind in harmony: an ancient Chinese way of exercise to achieve health and tranquility. North Canton, $\mathrm{OH}$ : Good News Publ.

DeMarco, M. A. (2016) Lesser-known Tai Chi lineages: Li, Wu, Sun, Xiong. Santa Fe, NM: Via Media.

Francke, H. (2005) "What's in a name?: conceptualizing the document concept". Literary and Linguistic Computing, Vol. 20 (1), 61-69.

Frohmann, B. (2007) "Multiplicity, materiality, and autonomous agency of documentation". A Document (Re)turn: contributions from a research field in transition. Eds: Roswitha Skare, Niels Windfeld Lund \& Andreas Vårheim. Frankfurt Am Main: Peter Lang, 27-39.

Frohmann, B. (2009) "Revisiting 'what is a document?"'. Journal of Documentation, Vol. 65 (2), 291-303. 
Geddes, G. (1991) Looking for the golden needle: an allegorical journey. Plymouth: MannaMedia.

Gorichanaz, T. \& Latham, K. F. (2016) "Document phenomenology: a framework for holistic analysis". Journal of Documentation, Vol. 72 (6), 11141133.

de Graffenried, S. (2007) Anatomy of Yang family Tai Chi. Nomentira Publications.

Grenersen, G. (2012) "What is a document institution? A case study from the South Sámi community". Journal of Documentation, Vol. 68 (1), 127-133.

Grenersen, G., Kemi, K. \& Nilsen, S. (2016) "Landscapes as documents: the relationship between traditional Sámi terminology and the concepts of document and documentation". Journal of Documentation, Vol. 72 (6), 1-18.

I Ching or Book of Changes: the Richard Wilhelm translation (1967). London: Penguin.

Irvine-Smith, S. (2015) "From object to mediator: the agency of documents". Proceedings from the Annual Meeting of the Document Academy, Vol. 2, article 4. Availbale at: http://ideaexchange.uakron.edu/docam/vol2/iss1/4/

Jwing-Ming, Yang (2001) Tai Chi secrets of the Wŭ \& Li styles: Chinese classics, translations, commentary. Rosindale, MA: YMMA Publication Centre.

Lao Tzu (1997) Tao te Ching: translated with notes by Arthur Waley. Ware: Wordsworth.

Latham, K. F. (2012) "Museum object as document: using Buckland's information concepts to understand museum experiences". Journal of Documentation, Vol. 68 (1), 45-71.

Lee, T. (2015) Power of Chakra and Tai Chi: how to reach spiritual, mental and physical balance using Tai Chi and Chakra. CreateSpace Independent Publishing Platform.

Lund, N. W. (2004) "Documentation in a complementary perspective". Aware and responsible: papers of the Nordic-International Colloquium on Social and Cultural awareness and responsibility in Library, Information and Documentation Studies (SCARLID). Ed: W. Boyd Rayward. Lanham, ML: Scarecrow Press, 93-102. 
Lund, N. W., Gorichanaz, T. \& Latham, K. F. (2016) "A discussion on document conceptualization". Proceedings of the Document Academy, Vol. 3 (2), article 1. Available at:

http://ideaexchange.uakron.edu/docam/vol3/iss2/1/

Maak, M. N. (2004) "The lady and the antelope: Suzanne Briet's contribution to the French documentation movement". Library Trends, Vol. 52 (4), 719-747.

Man Ching, Cheng (1985) Cheng Tzu's thirteen treatises on T'ai Chi Ch'uan: translated by Benjamin Pang Jeng Lo and Martin Inn. Berkeley, CA: Blue Snake Books.

Muir, G. (2008) Yang style traditional long form T'ai Chi Ch'uan: as taught by master T. T. Liang. Berkeley, CA: Blue Snake Books.

Nery, R. M., Zanini, M., de Lima, J. B., Bühler, R. P., da Silveira, A. D. And Stein, R. (2015) "Tai Chi Chuan improves functional capacity after myocardial infarction: a randomized clinical test". American Heart Journal, Vol. 169 (6), 854-860.

Nicolini, D. (2012) Practice theory, work \& organization: an introduction. Oxford: Oxford Univ. Press.

Olson, S. A. (2001) Ta'i Chi accoring to the I Ching: embodying the principles of the Book of Changes. Rochester, VT: Inner Traditions.

Olson, S. A. (2011) Tai Ji Treatise: attributed to the Song Dynasty daoist priest Zhang Sanfeng. Phoenix, AZ: Valley Spirit Arts.

Olsson, M. \& Lloyd, A. (2016) "Being in place: embodied information practices". Information Research, Vol 22 (1), CoLIS paper 1601. Available at: http://www.informationr.net/ir/22-1/colis/colis1601.html

Plotinsky, A. (2012) Niels Bohr and complementarity: an introduction. New York: Springer.

Russo, C. (2016) "The forgotten (female) pioneers of Tai Chi in the west". Vice/Fightland Blog, Mars 29, 2016. Available at:

http://fightland.vice.com/blog/the-forgotten-female-pioneers-of-tai-chi-in-the$\underline{\text { west }}$

Skare, R. (2009) "Complementarity: a concept for document analysis?". Journal of Documentation, Vol. 65 (5), 834-840. 
Tai Chi Classics: translated with commentary by Waysun Liao (1990) Boston: Shambhala.

Turner, D. (2007) "Conceptualizing oral documents". Information Research, Vol 12 (4), paper colis32. Available at:

http://www.informationr.net/ir/12-4/colis/colis32.html

Turner, D. (2012a) "Oral documents in concept and in situ, part I: grounding an exploration of orality and information behavior". Journal of Documentation, Vol. 68 (6), 852-863.

Turner, D. (2012b) "Oral documents in concept and in situ, part II: managerial decrees". Journal of Documentation, Vol. 68 (6), 864-881.

Wayne, P. M. \& Fuerst, M. L. (2013) The Harvard Medical School guide to Tai Chi: 12 weeks to a healthy body, strong heart and sharp mind. Boulder, CO: Shambhala.

Zhenshan, Zhong (2013) "On listening Jin and understanding Jin: my view on listening energy and understanding energy in Tai Chi Chuan". The Journal of the International Yang Tai Chi Chuan Association, No. 33, summer 2013, 4-6.

\section{APPENDIX}

\section{Some online Tai Chi resources}

Slanted Flying. General Tai Chi online journal, discussing all aspects of Tai Chi pratice and philosophy.

http://slantedflying.com/

International Yang Family Tai Chi Chuan Association.

http://www.yangfamilytaichi.com/home.php

Chen Xiaowang World Taijiquan Association.

http://www.chenxiaowang.com/

Brennan Translation. Renowned translations of Tai Chi and Martial Arts classics and manuals. 
https://brennantranslation.wordpress.com/

Best Tai Chi Videos Online. Major collection of Tai Chi videos, many of historical significance.

http://taichivideos.org/

World Tai Chi \& Qigong Day. General site drawing on all forms of Tai Chi related news and resources, not least medical. Based on World Tai Chi \& Qigong Day, occurring annualy on the last Saturday of April.

http://www.worldtaichiday.org/ 